\title{
El delito como injusto culpable. Sobre la conexión funcional entre el dolo y la consciencia de la antijuridicidad en el derecho penal chileno
}

\author{
Juan Pablo Mañalich Raffo*
}

Tratándose de acciones no permitidas, no hay objeto de error o desconocimiento que sea más importante que, precisamente, su carácter de no permitidas.

(Karl Binding, Die Normen und ibre Übertretung II, 2.)

\section{RESUMEN}

El artículo propone una comprensión estructural del concepto dogmático de delito, diferenciándolo del concepto de hecho punible, y validando su definición tradicional como "injusto culpable". Sobre esta base, se ofrece una reconstrucción de la conexión funcional entre el injusto subjetivo y la culpabilidad, para después especificar cómo dicha conexión se ve expresada en la relación funcional que cabe reconocer entre el dolo y la consciencia de la antijuridicidad. La tesis central, a este respecto, consiste en la proposición de que sólo en una atribución de culpabilidad definida por la consciencia de la antijuridicidad puede reflejarse el carácter doloso del injusto. Sobre esta base, se sugiere una relectura de la regulación legal en cuanto al régimen de punibilidad y penalidad aplicable a los casos de error de probibición vencible, que admite caracterizarse como una defensa de la solución postulada por la "teoría del dolo" a través del aparato conceptual de la "teoría de la culpabilidad".

Delito - culpabilidad - dolo

* Abogado, Doctor en Derecho, Profesor asociado del Departamento de Ciencias Penales de la Facultad de Derecho, Universidad de Chile, Av. Santa María 076, $4^{\circ}$ Piso, Providencia, Santiago de Chile. jpmanalich@derecho.uchile.cl

El autor agradece la generosa colaboración de Italo Reyes Romero, ayudante ad honorem del Departamento de Ciencias Penales, en la edición del texto, así como el valioso comentario de Javier Contesse Singh, investigador del Centro de Estudios de la Justicia, ambos de la Facultad de Derecho de la Universidad de Chile.

Artículo recibido el 30 de marzo de 2011 y aceptado para su publicación por el Comité Editorial el 27 de mayo de 2011. 


\title{
Crime as a blameworthy wrong: the functional connection between criminal intention and normative knowledge in Chilean law
}

\begin{abstract}
This article argues for a structural understanding of the doctrinal concept of crime, suggesting that we should distinguish it from the idea of the actus reus (hecho punible), thus validating the traditional definition of crime as a blameworthy wrongful action (injusto culpable). On this ground, the author reformulates the functional connection between the subjective elements of crime (mens rea) and blameworthiness, in order to specify how such connection expresses itself in the functional connection that we should acknowledge between criminal intention (dolo) and the awareness over the permissibility of the action. In this regard, the central thesis is the following proposition: only when blameworthiness implies normative knowledge can this judgment express the intentional character of the crime. Using this as a theoretical framework, the author suggests that we reinterpret the legal regulation of excusable mistakes of law, as a defence or as a mitigating factor. This solution can, in turn, be categorized as a defence of the solution that was first offered by the so called "teoria del dolo" (intent theory) through the conceptual apparatus of the "teoría de la culpabilidad" (culpability theory).
\end{abstract}

Crime - criminal intention - culpability

\section{FunCión VERSUS ESTRUCTURA}

6 67 o queremos practicar sociología ni retórica, sino jurisprudencia” ${ }^{\text {. Estas }}$ palabras de Karl Binding pueden ser tomadas como la expresión subliminal de un compromiso con una cierta comprensión de la tarea de la dogmática jurídico-penal, que podría ser definida como "estructural". Esto quiere decir que la tarea de la dogmática pasa a quedar identificada -al menos en lo nuclear- con un trabajo intelectual de clarificación y sistematización de estructuras. Y la razón para iniciar esta presentación citando a Binding radica en que los términos hegemónicos del discurso de la dogmática jurídico-penal contemporánea hacen especialmente improbable la adopción de un punto de partida metódicamente estructural, en el sentido ya indicado. Y esos términos hegemónicos, adversos a la cultivación de una dogmática estructural, no son sino los términos del así llamado "funcionalismo".

Lo distintivo de una comprensión funcional de la tarea de la dogmática jurídico-penal consiste en una reorientación de las categorías que constituyen el aparato conceptual de la dogmática hacia la función directamente atribuida a la práctica cuya operación es reconstruida a través de esas categorías ${ }^{2}$. En lo esencial, el funcionalismo ha traído consigo

${ }^{1}$ Binding, K., Die Normen und ibre Übertretung I, 4a ed., Scientia Verlag, Aalen, 1965 [orig.: 1922], p. 483.

${ }^{2}$ No es necesario entrar aquí en la descripción exhaustiva de las (a veces muy) distintas corrientes que son agrupadas bajo la etiqueta "funcionalismo", según cómo se articule la funcionalidad atribuida al derecho penal, de lo cual resulta la conocida y algo caricaturesca contraposición de un funcionalismo teleológico- 
la validación de una descripción sociológica de la operación del "sistema penal" como supuestamente vinculante para la elaboración del discurso dogmático. En el ámbito de la teoría de la pena, ello se ha traducido en la consolidación de la teoría de la prevención general positiva como la concepción funcionalista de la pena estatal. En el ámbito de la teoría del delito, ello ha tenido como correlato preciso el aparecimiento y la voraz propagación de la teoría de la imputación objetiva, cuya evolución reciente puede ser descrita, sin demasiada injusticia, como un proceso de hipertrofia de una categoría que tendría que ser capaz de resolver prácticamente la generalidad de los problemas de atribución de responsabilidad jurídico-penal, y en términos tales que también los problemas más tradicionales de la dogmática de la parte especial -por ejemplo, la determinación de los presupuestos del engaño típico en el ámbito de la estafa- podrían ser adecuadamente reformulados como genuinos problemas de imputación objetiva. Así, el éxito de la cruzada funcionalista se produce al modo de una erosión -y, en definitiva, disolución- de sofisticadas categorías y distinciones dogmáticas, que constituyen el resultado de un largo proceso de elaboración histórica. Especialmente característicos, a este respecto, resultan ser los alegatos de que determinadas distinciones -como la diferenciación misma entre injusto y culpabilidad-serían puramente "didácticas" ${ }^{3}$, o bien -como la diferenciación entre autoría y participación- puramente "cuantitativas" ${ }^{\text {. }}$

En lo que sigue se intentará ofrecer una defensa de una comprensión estructural de la tarea de la dogmática jurídico-penal, en referencia directa al ámbito en que su pretensión de sistematicidad -esto es, de rigurosidad en la construcción estructural-a primera vista es mayor, a saber: el ámbito de la así llamada teoría general del delito. Y el énfasis estará puesto en demostrar la vigencia de la definición dogmática de "delito" como "injusto culpable”, también en atención a las exigencias que impone la reconstrucción racional de la regulación plasmada en el Código Penal chileno. Y no porque esa reconstrucción sea posible prescindiendo de la función que cabe atribuir a las reglas con arreglo a las cuales se fundamenta la eventual responsabilidad jurídico-penal de una persona, sino más bien porque dicha función sólo se realiza estructuralmente: sin estructura -esto es, sin forma-, la apelación a la función se desvanece en algo que ciertamente habría irritado a Binding: retórica encubierta bajo vocabulario sociológico.

\section{LOS CONCEPTOS DE “DELITO” Y “HECHO PUNIBLE”}

Para dar cuenta siquiera inicialmente de cuáles pueden ser algunas de las implicaciones de la adopción de un punto de vista funcional para la elaboración dogmática del

valorativo (o "moderado") y un funcionalismo sistémico (o "radical”). Baste con asumir que la brevísima descripción ofrecida en el texto principal sugiere un mínimo "parecido de familia".

3 Radicalmente Lesch, H., Der Verbrechensbegriff, Carl Heymanns Verlag, Colonia, 1999, p. 207: "Culpabilidad jurídico-penal, injusto penal y crimen (hecho punible) sólo como sinónimos pueden ser adecuadamente reformulados en un sistema funcional del derecho penal”.

${ }^{4}$ Véase, por ejemplo, van Weezel, A., "Intervención delictiva y garantismo penal”, en Zeitschrift für Internationale Strafrechtsdogmatik 8, 2009, pp. 440 ss. 
concepto de delito, cabría detenerse en la siguiente afirmación, de un reputado exponente de lo que cabría calificar como un programa de funcionalismo moderado y reflexivo: "una teoría teleológico-funcional [...] del delito no puede excluir de su ámbito a ninguno de los factores determinantes de la imposición o no de una pena" ${ }^{5}$. Este llamado de atención por parte de Silva Sánchez, en cuanto a la necesidad de una ampliación del objeto tradicionalmente reservado a la teoría general del delito, resulta de máxima significación, teniendo a la vista cuál tendría que ser el desarrollo consistente de semejante programa de teorización: el concepto dogmático de delito ciertamente tendría que extenderse de modo tal de abarcar, ya sin vacilaciones, la problemática categoría de la "punibilidad" (stricto sensu). Pero no sólo eso. Pues dentro del conjunto de condiciones de las cuales depende la imposición judicial de una determinada sanción penal figura, asimismo, una serie de variables que, a primera vista al menos, se presentan como de índole estricta o preferentemente procesal, de las cuales también tendría que ocuparse, sin embargo, una teoría teleológico-funcional del delito ${ }^{6}$.

Aquí habrá de sostenerse, como primera tesis, que el compromiso con una dogmática de vocación estructural nos debería llevar a resistir ese programa de ampliación. Y no, ciertamente, porque la dogmática de la parte general no deba ocuparse de ese conjunto de factores a cuyo déficit de teorización se refiere, con razón, el llamado de atención de Silva Sánchez. El problema, más bien, es que ese programa de ampliación conduce al colapso de una distinción dogmática de máxima relevancia, a pesar del olvido generalizado en que ella se encuentra sumida, a saber: la distinción entre el concepto de delito y el de hecho punible. Y para advertir la importancia de esta distinción, lo más razonable es acudir a su formulación más aguda y consistente, que es, como se intentará mostrar, la que le diera Binding.

Desde un punto de vista propiamente jurídico, por "delito" cabe entender el quebrantamiento imputable de una norma de comportamiento. Pero como célebremente apuntara Binding, la norma quebrantada por el autor del hecho no puede ser, al mismo tiempo, la norma que establece la habilitación para la imposición de una determinada sanción penal como la consecuencia jurídica de la realización de su supuesto de hecho, esto es, del respectivo tipo delictivo ${ }^{7}$. Pues el autor del hecho por definición no contraviene esta norma de sanción penal -que Binding denominara "ley penal"-, sino que realiza, antes bien, el antecedente de su aplicación. Luego, si ha de tener sentido la idea de que el autor del hecho delictivo quebranta una norma, de lo cual depende, en efecto, la posibilidad misma de su antijuridicidad, entonces esa norma tiene que ser entendida como un estándar de comportamiento que es conceptualmente primario frente a la respectiva norma de sanción penal. Que la norma de comportamiento no se encuentre

${ }^{5}$ Silva Sánchez, J., "Introducción: Dimensiones de la sistematicidad de la teoría del delito”, en Wolter y Freund (ed.), El sistema integral del Derecho penal, Marcial Pons, Madrid/Barcelona, 2004, p. 22.

${ }^{6}$ Críticamente al respecto, en lo tocante al estatus de las reglas sobre prescripción de la acción penal, Mañalich, J.P., Terror, pena y amnistía, Flandes-Indiano, Santiago, 2010, pp. 221 ss.

${ }^{7}$ Binding, K., Die Normen und ibre Übertretung I, 4a ed., Scientia Verlag, Aalen, 1965 [orig.: 1922], pp. 3 ss., 35 ss. 
explícitamente formulada por ley -a diferencia, por ejemplo, de lo que ocurre el decálogo del libro del Éxodo- no obsta a que ella pueda ser inferida pragmáticamente a partir de la correspondiente norma de sanción. Pues de esto depende, en efecto, que el hecho punible pueda ser entendido como una contravención del derecho.

De esta manera, la norma de comportamiento y la norma de sanción se diferencian, desde ya, en atención a su estructura. La norma de comportamiento es un estándar categórico de comportamiento jurídicamente correcto; la norma de sanción, en cambio, es una regla condicional que sujeta la aplicabilidad de una determinada consecuencia punitiva a la realización de un determinado supuesto de hecho, el cual ordinariamente representa la formulación invertida de la correspondiente norma de comportamiento ${ }^{8}$. Así por ejemplo, la descripción "el que mate a otro" constituye la formulación invertida del comportamiento exigido por la prohibición de matar a otro (ser humano) ${ }^{9}$.

Pero la norma de comportamiento y la norma de sanción también se diferencian desde el punto de vista de quiénes son sus respectivos destinatarios. La norma de comportamiento se encuentra dirigida a cualquiera persona que pueda llegar a estar en posición o bien de abstenerse de ejecutar la acción prohibida o bien de ejecutar la acción ordenada, según se trate de una prohibición o de un mandato; sólo tratándose de normas cuyo quebrantamiento constituye un delito especial (propio)-por ejemplo, un delito ministerial o de funcionario público- se encuentra restringido el círculo de sus destinatarios, precisamente, a quienes exhiben la cualificación personal en cuestión - por ejemplo, la calidad de funcionario público ${ }^{10}$.

La norma de sanción, en cambio, no se encuentra dirigida al eventual autor del hecho delictivo, en el sentido de que la norma de sanción pudiera imponer a éste un deber de tolerar la punición. Pues de ser así, habría que admitir la posibilidad de un regreso al infinito: además de la pena correspondiente al ("primer") delito, el autor de éste estaría expuesto a una pena ulterior por la eventual infracción del supuesto deber de soportar la punición, y así sucesivamente ${ }^{11}$. Pero en rigor, según Binding, la norma de sanción tampoco tiene como destinatario al tribunal competente para la eventual imposición de la pena, así como tampoco a los funcionarios responsables de su ejecución. Pues los deberes que recaen sobre éstos son impuestos por normas que los vinculan en su calidad de portadores de sus cargos. El tribunal competente debe imponer la pena señalada por la norma de sanción al delito, pero no en virtud de esta misma norma de sanción, sino en virtud de las normas que le obligan, al desempeñar su magisterio, a

${ }^{8}$ La expresión "ordinariamente" quiere decir, más precisamente: siempre que se trate de la tipificación del correspondiente delito-base, que representa la forma más simple de quebrantamiento de la respectiva norma de comportamiento, sobre la cual la regulación legal puede construir modalidades más complejas, como es el caso, por ejemplo, cuando la ley tipifica formas calificadas o privilegiadas sobre la base de la misma forma básica de injusto. Para este concepto de delito-base o "delito genérico" (Gattungsdelikt), véase ibid., pp. 190 ss.

\footnotetext{
${ }^{9}$ Ibid., pp. $42 \mathrm{~s}$.

${ }^{10}$ Ibid., pp. $126 \mathrm{~s}$.

${ }^{11}$ Ibid., pp. 13 s.
} 
fallar conforme a derecho ${ }^{12}$. Y finalmente, ni siquiera el Estado puede ser entendido como sujeto inmediatamente obligado por una norma de sanción penal. Pues el Estado puede renunciar, a través de una amnistía o un indulto, a ejercer el derecho punitivo que para él se sigue de la perpetración del delito por parte del destinatario de la respectiva norma de comportamiento así quebrantada ${ }^{13}$. El "verdadero significado" de la norma de sanción penal se encuentra, según Binding, en que ella no constituye una norma que imponga, directamente, deber alguno. Se trata, antes bien, de una "proposición jurídica afirmativa", cuya finalidad consiste en configurar derechos punitivos y determinar su contenido, y esto siempre en interés tanto del titular del respectivo ius puniendi como de la persona en contra de la cual ese derecho es ejercido ${ }^{14}$.

Lo anterior sugiere que entre la norma de comportamiento y la norma de sanción también cabe reconocer una diferencia teleológica, relativa a sus respectivos criterios de legitimación material. Si la finalidad de la norma de sanción se encuentra en el establecimiento concluyente de determinados derechos y deberes punitivos a consecuencia del quebrantamiento (imputable) de una determinada norma de comportamiento, la finalidad de ésta sólo puede consistir, en cambio, en la evitación de menoscabos -sea en la forma de una lesión, un peligro concreto o un peligro abstracto- para un determinado bien jurídico, que así se constituye como el objeto de protección de esa norma ${ }^{15}$. De ahí que la protección jurídico-penal de bienes jurídicos sólo pueda ser entendida como una protección mediatizada o indirecta: el derecho penal asegura, a través de las correspondientes normas de sanción, la vigencia de determinadas normas de comportamiento orientadas a la protección de determinados bienes jurídicos, en tanto estas normas operan como razones para la acción dirigidas a la evitación de alguna forma de menoscabo del bien jurídico respectivamente protegido.

Sobre esta base, se vuelve posible postular una demarcación exacta de las nociones de delito y hecho punible. El delito constituye el quebrantamiento imputable de una determinada norma de comportamiento, esto es, un injusto culpable. El hecho punible -o "crimen" (Verbrechen), en palabras de Binding-, en cambio, sólo se corresponde con aquel delito que además satisface aquellas condiciones ulteriores de las cuales puede depender, específicamente, su merecimiento y necesidad de pena, por referencia a variables delictivas (por ejemplo, la eventual clausura de la punibilidad de la imprudencia) o bien extradelictivas (por ejemplo, el reconocimiento de alguna excusa legal absolutoria), las cuales pueden estar fijadas en la propia norma de sanción ("principal”) o bien en determinadas reglas que la complementan. De esta manera, la norma de sanción representa un filtro que determina si y en qué medida resulta punible un delito determinado, esto es, el quebrantamiento imputable de una determinada norma de comportamiento ${ }^{16}$.

12 Ibid., pp. 14 ss.

${ }^{13}$ Para un desarrollo detallado de este punto, véase Mañalich, J.P., Terror, pena y amnistía, FlandesIndiano, Santiago, 2010, pp. 109 ss., 135 ss.

${ }^{14}$ Binding, K., Die Normen und ibre Übertretung I, 4ª ed., Scientia Verlag, Aalen, 1965 [orig.: 1922], pp. $19 \mathrm{~s}$.

15 Ibid., pp. 338 ss.

${ }^{16}$ Ibid., pp. 132 ss., 194 ss., 426 ss. 
Todo hecho punible tiene como base un correspondiente hecho delictivo, pero no todo hecho delictivo llega a constituir un hecho punible.

En la medida en que la definición legal del inc. $1^{\circ}$ del art. $1^{\circ}$ del Código Penal introduce una cláusula expresamente referida al nivel de la norma de sanción, al exigir que la acción u omisión en cuestión esté “castigada por la ley”, esta definición de "delito", en el nivel de su reconstrucción dogmática, representa más bien una definición de "hecho punible" 17 .

\section{El Delito COMO injusto CUlPable}

Lo que se impone ahora es una revisión de algunas de las implicaciones de una comprensión del delito como injusto culpable. Por "injusto" cabe entender aquí, por de pronto, una contravención del derecho; más precisamente, una contravención de una determinada norma de comportamiento que reclama validez jurídica. Pero lo distintivo del delito como variante de injusto, a este respecto, está constituido por el carácter reflexivo de esa contravención del derecho. El delito no es una mera contravención, sino más bien contradicción del derecho. Es precisamente esto lo que, según Hegel, distingue al "crimen" como forma de injusto: se trata de una "lesión del derecho en cuanto derecho", en la medida en que el crimen representa un juicio ("negativo-infinito") de parte de su autor, que desconoce la pretensión de vigencia del derecho ${ }^{18}$.

Dicho en otros términos, el delito cuenta como un hecho que es portador de un determinado valor declarativo, que es independiente de cuál sea su específica configuración fenoménica: un asesinato, un hurto o una evasión tributaria, etc., son todos hechos que portan, en el correspondiente nivel de abstracción, un mismo significado ${ }^{19}$, consistente en una falta de reconocimiento de la respectiva norma de comportamiento como razón eficaz para la acción. Y de ahí también que la pena, en tanto respuesta al delito por la cual se produce una cancelación de la cancelación del derecho, sólo pueda ser adecuadamente entendida como un hecho igualmente portador de significado. A través de la pena se produce la declaración de que la norma quebrantada por el autor del hecho delictivo es una norma que conserva su vigencia ${ }^{20}$.

El reconocimiento de esta función declarativa o comunicativa de la pena, empero, exige advertir, desde ya, que la pena no es una "mera" declaración. Y esto se sigue del hecho, estrictamente simétrico, de que tampoco el delito constituye una "mera" declaración. Pues en tanto expresión de una falta de reconocimiento de la respectiva norma como razón eficaz para la acción, el delito sólo puede consistir, auténticamente, en la realización

${ }^{17}$ Ello fue claramente advertido por Novoa Monreal, E., Curso de Derecho Penal Chileno I, $3^{\mathrm{a}}$ ed., Editorial Jurídica de Chile, Santiago, 2005, p. 223, en su crítica de la definición legal del art. $1^{\circ}$ del Código Penal.

${ }^{18}$ Hegel, G.F.W., Grundlinien der Philosophie des Rechts, Werke 7, Suhrkamp, Frankfurt a.M., 1986, $\S 95$.

${ }^{19}$ Ibid., $\$ 101$.

${ }^{20}$ En detalle al respecto Mañalich, J.P., Terror, pena y amnistía, Flandes-Indiano, Santiago, 2010, pp. 76 ss., 89 ss. 
imputable de una forma de comportamiento que es contraria a lo que esa norma prohíbe u ordena. A modo de ejemplo: una persona que en una plaza pública grita "la prohibición de matar a otro no vale para mí" no expresa una falta de reconocimiento de la prohibición de matar a otro como razón eficaz para la acción. Antes bien, sólo la realización de una forma de comportamiento que es incompatible con la realización de la intención de evitar matar a otro representa una puesta en cuestión de la vigencia de esa norma ${ }^{21}$.

Lo anterior quiere decir, en términos de la teoría de los actos de habla, que el hecho delictivo no cuenta como una declaración explícitamente performativa ${ }^{22}$. Y en tanto la punición haya de ser entendida como la respuesta jurídica al hecho delictivo en sus propios términos, entonces ella tampoco puede ser adecuadamente entendida como una declaración explícitamente performativa ${ }^{23}$. La pena no es la mera declaración de un reproche dirigido al autor de un hecho delictivo, porque la mera declaración de un reproche usualmente no equivale, fuera del contexto de relaciones interpersonales íntimas, a la efectiva realización de un reproche. La necesidad de evitación de un déficit de objetivación de la respuesta punitiva al hecho delictivo explica que la pena, en el plano de su facticidad, tenga que operar como la irrogación de un mal que el condenado ha de soportar coercitivamente . $^{24}$.

Para que el hecho delictivo se constituya como portador de tal valor declarativo, es necesario que el mismo cuente como la expresión objetivada de una falta de seguimiento de la norma. Ello presupone, sin embargo, que el autor del hecho haya sido capaz de seguir la norma, de modo tal que en su no-seguimiento se manifieste un déficit reprochable de fidelidad al derecho. Las condiciones de las cuales depende la efectiva capacidad de seguimiento de la norma por parte de su destinatario son identificadas por un conjunto de reglas, que cabe denominar, técnicamente, "reglas de imputación”. El hecho resulta imputable, entonces, cuando se satisfacen las condiciones, fijadas en las correspondientes reglas de imputación, de las cuales depende que del destinatario de la norma pueda esperarse el seguimiento de ésta, es decir, su reconocimiento práctico como razón eficaz para la acción ${ }^{25}$.

${ }^{21} \mathrm{Y}$ esto explica que el sentido delictivo de un hecho constitutivo de tentativa siempre sea imperfecto, esto es, deficitario. Pues lo que el autor de una tentativa (de delito) declara -esto es, que no reconoce la norma como razón eficaz para la acción- no es congruente con la descripción objetiva del comportamiento que le es imputable. Al respecto Mañalich, J.P., Nötigung und Verantwortung, Nomos, Baden-Baden, 2009, pp. 61 ss.; Mañalich, J.P., "Norma e imputación como categorías del hecho punible”, en Revista de Estudios de la Justicia 12, 2010, pp. $180 \mathrm{~s}$.

22 Para una revisión panorámica de las categorías fundamentales de la teoría analítica de los actos de habla, véase Mañalich, J.P., “¿Reglas del entendimiento? Acerca de la ‘juridificación’ de la comunicación en la pragmática universal de Jürgen Habermas”, en Estudios Públicos 119, 2010, pp. 127 ss., 135 ss., con ulteriores referencias. En especial acerca del estatus de las expresiones explícitamente performativas (o realizativas), Mañalich, J.P.: Nötigung und Verantwortung, Nomos, Baden-Baden, 2009, pp. 195 ss.

${ }^{23}$ Mañalich, J.P., Terror, pena y amnistía, Flandes-Indiano, Santiago, 2010, pp. 82 ss.

${ }^{24}$ Hegel, G.F.W., Grundlinien der Philosophie des Rechts, Werke 7, Suhrkamp, Frankfurt a.M., 1986, $\S 101$. En detalle acerca de este momento coercitivo de la pena estatal, Mañalich, J. P., Terror, pena y amnistía, Flandes-Indiano, Santiago, 2010, pp. 95 ss.

${ }^{25}$ En detalle al respecto Kindhäuser, U., Gefährdung als Straftat, Vittorio Klostermann, Frankfurt a.M., 1989, pp. 29 ss., 62 ss.; Mañalich, J.P., Nötigung und Verantwortung, Nomos, Baden-Baden, 2009, 
El suceso con relevancia jurídico-penal, identificado como el objeto de una posible imputación, se corresponde con lo que tradicionalmente se designa como el injusto objetivo del hecho, que equivale a un comportamiento que, objetivamente, resulta contrario a una norma de prohibición o de mandato, y que no resulta cubierto por alguna norma permisiva constitutiva de una posible causa de justificación -esto es, un comportamiento antinormativo, que (sólo) en el ámbito de los delitos puros de resultado se identifica con la causación del resultado típico (no cubierta por una norma permisiva constitutiva de una causa de justificación). Para que este comportamiento adquiera carácter delictivo, entonces, es necesario que el mismo sea imputable al destinatario de la norma respectiva. Y esta imputabilidad se articula en un juicio de dos niveles, cada uno de los cuales se corresponde con una dimensión específica de la capacidad de seguimiento de la norma cuyo ejercicio se espera de su destinatario.

Por una parte, el comportamiento (objetivamente) antinormativo tiene que haber sido intencionalmente evitable para el destinatario de la norma, en atención a su capacidad física y cognitiva de realizar una determinada intención, esto es, su "capacidad de acción”. En la medida en que, con arreglo al principio ultra posse nemo obligatur, el destinatario de la norma sólo queda vinculado (u "obligado") por ésta según su propia capacidad, el resultado positivo de la imputación en este primer nivel consiste en la constitución del hecho como una infracción de deber. Y son justamente los presupuestos de la imputación del hecho a título de infracción de deber los que fungen como elementos de lo que tradicionalmente se denomina el "injusto subjetivo", a saber: la capacidad física de evitación intencional y el conocimiento de las circunstancias fácticas relevantes, definido como "dolo" 26 .

No satisfaciéndose este presupuesto ordinario de la imputación, por encontrarse el destinatario de la norma en una situación de incapacidad física de acción o bien de déficit cognitivo que implique una inexistencia de dolo, subsiste la posibilidad de una imputación a título de infracción de deber, a pesar de la existencia del déficit en cuestión, fundada en la responsabilidad del sujeto por su propio déficit de imputabilidad. El criterio para esta "imputación extraordinaria" se encuentra en la infracción de una exigencia (o "incumbencia") de cuidado, de modo tal que, en atención al correspondiente injusto subjetivo, el hecho haya de ser caracterizado como "imprudente" 27.

pp. 46 ss.; Mañalich, J.P., "Norma e imputación como categorías del hecho punible”, en Revista de Estudios de la Justicia 12, 2010, pp. 174 ss.

${ }^{26}$ Los elementos subjetivos especiales del tipo delictivo, por el contrario, en tanto contribuyen a la identificación del objeto de la prohibición -por ejemplo, en la forma de una tendencia interna trascendente, tal como el ánimo de enriquecimiento en la estafa-, son componentes de la descripción del objeto de la imputación. Pues se trata aquí de circunstancias subjetivas que contribuyen a determinar, compensando la impaciencia legislativa expresada en la anticipación formal del momento de la consumación -véase Binding, K., Lebrbuch des Gemeinen Deutschen Strafrechts I, 2a ed., Wilhelm Engelmann, Leipzig, 1902, pp. 11 ss.-, el específico menoscabo del bien jurídico protegido que tiene relevancia típica.

27 Al respecto Kindhäuser, U., Gefährdung als Straftat, Vittorio Klostermann, Frankfurt a.M., 1989, pp. 62 ss., 102 ss.; Mañalich, J. P., Nötigung und Verantwortung, Nomos, Baden-Baden, 2009, pp. 67 ss. Para el concepto de imputación extraordinaria, véase en detalle Hruschka, J., "La imputación ordinaria y 
De este modo, la forma paradigmática de injusto (pleno) -que es la del delito consumado- se identifica con el comportamiento contrario a una norma que protege un determinado bien jurídico, que resulta subjetivamente imputable a título de infracción de deber. Y frente a esto, lo distintivo de la estructura delictiva de la tentativa, por su parte, se agota en que en ella se trata de la imputabilidad como infracción de deber de un comportamiento que no alcanza a satisfacer la descripción de la cual depende su específica antinormatividad, esto es, su valor declarativo objetivo como quebrantamiento de la norma.

Recién ahora es posible examinar, más de cerca, qué está en juego con la definición de "delito" como instancia de injusto culpable. A este respecto, Binding terminó inclinándose por la siguiente solución: la especificidad del injusto que es eventualmente delictivo en sentido jurídico-penal no es reconocible como tal con independencia de la culpabilidad ${ }^{28}$. Ello, porque esta forma de injusto consiste, específicamente, en la desautorización de una determinada norma de comportamiento. Según ya se sostuviera, el valor declarativo del hecho delictivo consiste en la objetivación de una falta de reconocimiento de la norma como razón eficaz para la acción. Y que un hecho llegue a exhibir ese valor declarativo, de modo tal que a su autor pueda reprocharse un déficit de fidelidad a derecho, es en todo caso dependiente de que el hecho le sea definitivamente imputable como quebrantamiento de la norma en cuestión. Éste es el quid de la conexión funcional entre el injusto y la culpabilidad: el injusto que no alcanza a constituir un injusto culpable carece de relevancia jurídico-penal, porque recién la culpabilidad por el injusto fundamenta el carácter reprochable de ese injusto. Nada de esto, sin embargo, altera la corrección del argumento - "pálido”, según Jakobs- acerca de la necesidad lógica de diferenciar ya entre injusto (objetivo) y culpabilidad:

en todo caso, la falta de culpabilidad por la imposibilidad de conocer o cumplir la norma presupone que ésta exista como tal con independencia de su cognoscibilidad o de la posibilidad de cumplirla, por lo que aquello que es contrario a la norma, el injusto, puede también existir independientemente ${ }^{29}$.

La específica capacidad del destinatario de la norma que aparece como criterio de imputación en este nivel puede ser designada como su capacidad de motivación. La imputación de un hecho a título de culpabilidad requiere, primero, que el sujeto en cuestión, al momento del hecho, haya podido motivarse a evitar intencionalmente su

extraordinaria en Pufendorf', en del mismo, Imputación y derecho penal, Thomson/Aranzadi, Navarra, 2005, pp. 55 ss.

${ }^{28}$ Binding, K., Die Normen und ibre Übertretung I, 4a ed., Scientia Verlag, Aalen, 1965 [orig.: 1922], pp. 298 s. Al respecto véase Pawlik, M., “`¿El paso más importante de la dogmática de la última generación?'. Reflexiones para la diferenciación entre injusto y culpabilidad en derecho penal”, en, del mismo, La libertad institucionalizada. Estudios de filosofía jurídica y derecho penal, Marcial Pons, Madrid/Barcelona/ Buenos Aires, 2010, pp. 122 ss.

${ }^{29}$ Jakobs, G., "El concepto jurídico-penal de acción” en, del mismo, Estudios de Derecho Penal, Civitas, Madrid, 1997, p. 123. 
realización en pos del seguimiento de la norma; así como, en segundo término, que esa motivación le resultase exigible en la respectiva situación ${ }^{30}$.

Este doble requerimiento de capacidad y exigibilidad de una motivación conforme a la norma hace posible enunciar las condiciones precisas de cuya satisfacción depende la imputabilidad del injusto a título de culpabilidad. En primer lugar, es necesario que el destinatario de la norma dispusiera, al momento del hecho, de una constitución psíquica suficiente para esa motivación, lo cual falla tratándose de personas privadas de razón (art. $10 \mathrm{~N}^{\mathrm{o}} 1 \mathrm{CP}$ ), o bien -al menos en el ámbito del derecho penal de adultosde menores de edad (art. $\left.10 \mathrm{~N}^{\circ} 2 \mathrm{CP}\right)^{31}$. A estas situaciones de inculpabilidad por falta de capacidad de culpabilidad pueden equipararse los casos de error de prohibición -en el ámbito de los delitos de omisión, del correspondiente error de mandato-, esto es, de aquella forma de error que excluye la consciencia de la antijuridicidad del hecho. Pues el desconocimiento del carácter antinormativo del hecho vuelve contextualmente imposible que quien padece el error llegue a formarse la intención de evitar la realización del hecho en pos del seguimiento de la norma respectiva.

Junto a estas situaciones, en las cuales resulta excluida la capacidad motivacional de seguimiento de la norma en virtud de una determinada causa de inculpabilidad, el reproche de culpabilidad también puede verse excluido al configurarse una situación en que el ejercicio de esa capacidad de motivación, orientada al seguimiento de la norma, deje de ser exigible del sujeto en la concreta situación. En tales casos puede reconocerse, en consecuencia, una causa de exculpación, cuyo fundamento ha de encontrarse en que del destinatario de la norma no cabe esperar un sacrificio personal extraordinario ${ }^{32}$. Pues en tal caso, la falta de seguimiento de la norma deja de ser indicativa de un déficit de fidelidad al derecho que sea jurídico-penalmente reprochable. En principio al menos, puede asumirse que tanto el $\mathrm{N}^{\circ} 9$ como el recientemente incorporado $\mathrm{N}^{\circ} 11$ del art. 10 del Código Penal chileno establecen causas de exculpación fundadas en un criterio de falta de exigibilidad situacional de una motivación conforme a la norma ${ }^{33}$.

\footnotetext{
${ }^{30}$ En detalle Mañalich, J. P., Nötigung und Verantwortung, Nomos, Baden-Baden, 2009, pp. 46 ss., 279 ss.

${ }^{31}$ Esto se traduce en una interpretación del art. $10 \mathrm{~N}^{\circ} 2$ del Código Penal, con arreglo a la cual la condición de menor de 18 constituye una auténtica eximente de responsabilidad, al modo de una causa de inculpabilidad, bajo el régimen jurídico-penal "ordinario" o de adultos. La segunda parte de dicha disposición, por ende, reconoce la apertura de un régimen "extraordinario” de responsabilidad jurídico-penal para aquellas personas que, siendo incapaces de culpabilidad en el sentido del régimen ordinario, se encuentran ya en tránsito (biográfico) hacia la satisfacción de los presupuestos de esa capacidad, en circunstancias que la ley fija la edad de 14 años como el umbral mínimo de la extensión de ese proceso adquisitivo de capacidad de culpabilidad. Esto convierte el régimen de responsabilidad penal de menores adolescentes en un régimen irreductiblemente problemático -y más exactamente: paradójico-, precisamente porque las sanciones asociadas a ese régimen sólo parcialmente pueden reclamar significación retributiva. En todo caso, la interpretación del art. $10 \mathrm{~N}^{\circ} 2$ aquí sugerida implica que, siendo el menor de 18 años siempre incapaz de culpabilidad bajo el régimen ordinario de responsabilidad jurídico-penal, quien se vale de tal menor para la realización de un hecho delictivo es siempre, ceteris paribus, autor mediato.

32 Mañalich, J. P., Nötigung und Verantwortung, Nomos, Baden-Baden, 2009, pp. 303 ss., 314 ss.

${ }^{33}$ Ello depende de una interpretación del art. $10 \mathrm{~N}^{\mathrm{o}} 11$ como disposición que establecería una eximente al modo de un estado de necesidad exculpante. A favor de tal interpretación habla decisivamente, además del
} 
Pero también en este nivel cabe reconocer la posibilidad de una imputación extraordinaria, fundada en la responsabilidad del destinatario de la norma por su propio déficit de culpabilidad. Éste es el caso cuando el derecho desconoce la aplicabilidad de una causa de inculpabilidad por privación total de razón en una situación de intoxicación autoinducida, en el sentido de una actio libera in causa, como también cuando un eventual error de prohibición es calificado como vencible o superable.

\section{Culpabilidad POR el injusto}

Es justamente este último punto el que ofrece la oportunidad para preguntarse acerca de la conexión funcional que ha de reconocerse entre el injusto y la culpabilidad, cuya estructura puede expresarse mediante el enunciado de que el injusto constituye el objeto de referencia de la culpabilidad. Es decir: sólo hay un injusto culpable en la medida en que haya culpabilidad por el injusto.

En los términos del modelo analítico ya esbozado, la culpabilidad tiene que ser entendida como el conjunto de los presupuestos de cuya satisfacción depende la imputabilidad definitiva de una infracción personal de deber como un comportamiento que expresa un déficit reprochable de fidelidad al derecho. En esto consiste, precisamente, el énfasis terminológico de la antigua doctrina de la imputación, que identificaba la adscripción de culpabilidad por el hecho con una imputatio iuris ${ }^{34}$. Pues es recién en virtud de la adscripción de culpabilidad que la respectiva infracción de deber fundamenta el merecimiento de la específica consecuencia jurídica asociada al quebrantamiento imputable de la norma: el reproche jurídico-penal que se materializa en la (ejecución de la) pena.

Esto es decisivo para enfrentar adecuadamente el viejo "problema del destinatario", que tradicionalmente ha azotado a la teoría de las normas. Las capacidades individuales identificadas como condiciones (positivas) de la imputación no convierten a una persona en destinatario de la norma, dado que la norma no puede, por razones de necesidad estrictamente lógica, prescribir su propio seguimiento sin volverse autorreferente, lo cual lleva a un regreso al infinito ${ }^{35}$. Antes bien, esas capacidades determinan, en primer lugar -esto es, en el nivel del injusto (subjetivo)-, en qué medida la norma se concreta, situacionalmente, en un deber personal para uno cualquiera de sus destinatarios; y en segundo lugar - esto es, en el nivel de la culpabilidad -, en qué medida esa infracción

hecho de que la eximente sea aplicable a pesar de que el "mal que se evita" sea menor que el "mal causado", con tal que éste no sea "sustancialmente superior", la circunstancia $4^{\text {a }}$, cuya formulación contiene un criterio de falta de "exigibilidad razonable".

${ }^{34}$ Fundamental Hruschka, J., "Reglas de comportamiento y reglas de imputación”, en del mismo, Imputación y derecho penal, Thomson/Aranzadi, Navarra, 2005, pp. 27 ss., 30, 34 s.

${ }^{35}$ Mañalich, J. P., Nötigung und Verantwortung, Nomos, Baden-Baden, 2009, pp. 36 s., 43 ss.; Mañalich, J. P., "Norma e imputación como categorías del hecho punible", en Revista de Estudios de la Justicia 12, 2010, pp. 170 ss. 
de deber resulta personalmente reprochable. En tanto el derecho penal sea el derecho que regula las condiciones de imposición (y ejecución) de una sanción penal, y en tanto la imposición de una sanción penal - esto es, de una pena-dependa de la existencia de una infracción de deber reprochable, un injusto que no fundamente el correspondiente reproche, por no resultar personalmente imputable a título de culpabilidad, es un injusto que, como llegara a advertir Binding, carece de toda relevancia jurídico-penal.

Lo anterior puede ser trivialmente obvio, pero tiene consecuencias que están lejos de ser triviales ${ }^{36}$. Aquí es relevante fijar la atención en una de ellas: el dolo-entendido como consciencia (de las circunstancias) del hecho- que no llega a fundamentar la correspondiente consciencia de la antijuridicidad del hecho carece de relevancia, al menos directamente, para el reproche de culpabilidad ${ }^{37}$. Y como habrá de sostenerse, aquí se encuentra la clave para entender la equiparación que el Código Penal chileno hace, en su art. $2^{\circ}$, de las nociones de "dolo" y "malicia".

En este punto es importante detenerse, con algún cuidado, en la terminología utilizada. La consciencia de la antijuridicidad exigida como condición de culpabilidad es la consciencia de la antijuridicidad del hecho, y no una consciencia de la antijuridicidad "en abstracto" 38 . Es decir, la culpabilidad por el injusto exige la representación, por parte del sujeto de la imputación, de que el comportamiento de cuya imputabilidad se trata es contrario a derecho, y esto quiere decir: un comportamiento antinormativo. Esto implica, sin embargo, que sólo en relación con un hecho imputable a título de dolo es posible la constatación de la correspondiente consciencia ("actual”) de la antijuridicidad. Pues el dolo y la consciencia de la antijuridicidad se relacionan al modo de una actitud proposicional de primer orden y una actitud proposicional de segundo orden, respectivamente: mientras que actúa con dolo de homicidio quien se representa la posibilidad concreta de que su comportamiento cause la muerte de otro ser humano (sin que se den circunstancias que objetivamente satisfarían el supuesto de hecho de

${ }^{36}$ Desde ya, la siguiente: en la medida en que para la imposición de una medida de seguridad es necesaria la existencia de un injusto sin culpabilidad (art. $455 \mathrm{CPP}$ ), puede concluirse que una medida de seguridad no constituye una forma de reacción propiamente jurídico-penal. En este sentido, Pawlik, M., “ ¿El paso más importante de la dogmática de la última generación?’. Reflexiones para la diferenciación entre injusto y culpabilidad en derecho penal", en, del mismo, La libertad institucionalizada. Estudios de filosofía jurídica y derecho penal, Marcial Pons, Madrid/Barcelona/Buenos Aires, 2010, pp. 130 s.

${ }^{37}$ Véase Binding, K., Die Normen und ibre Übertretung II, 4ª ed., Scientia Verlag, Aalen, 1965 [orig.: 1922], pp. 402 ss., 680 ss., aunque entendiendo el dolo como una forma de culpabilidad que contiene, además del conocimiento de las circunstancias del hecho, el conocimiento de la antijuridicidad del mismo.

${ }^{38}$ Esto no quiere decir, en contra de lo recientemente sostenido por Neumann (véase Neumann U., "Regel und Sachverhalt in der strafrechtlichen Irrtumsdogmatik", en Paeffgen et al. (coord.), Strafrechtswissenschaft als Analyse und Konstruktion. Festschrift für Ingeborg Puppe zum 70. Geburtstag, Duncker \& Humblot, Berlín, 2011, pp. 174 ss.), que esa exigencia de concreción de la consciencia de la antijuridicidad implique la caracterización de ésta como el conocimiento del alcance de una regla (o norma). Pues la exigencia de la "referencia al tipo" (Tatbestandsbezogenheit) de la consciencia de la antijuridicidad se ve en todo caso salvaguardada en la medida en que al destinatario de la norma sólo pueda adscribirse la representación de la antijuridicidad del hecho en tanto pueda adscribírsele, al modo de un paso conceptualmente anterior, la representación de las circunstancias del hecho de las cuales depende -extensionalmente- la realización del respectivo tipo delictivo. 
una norma permisiva preferente) $)^{39}$, actúa con consciencia de la antijuridicidad propia del homicidio quien se representa la posibilidad concreta de que su comportamiento, bajo su descripción como la causación de la muerte de otro, sea contrario a una norma prohibitiva (no desplazada por una norma permisiva preferente) ${ }^{40}$.

Esto se sigue de que la antinormatividad de un comportamiento - esto es, su propiedad de ser contrario a una norma de prohibición o de mandato, no desplazada por alguna norma permisiva que pudiera operar como una causa de justificación - es una propiedad superviniente ${ }^{41}$, esto es, una propiedad secundaria en relación con aquellas propiedades primarias de cuya satisfacción depende que el comportamiento resulte contrario a aquella norma y no resulte, además, cubierto por alguna regla permisiva preferente (constitutiva, en tal medida, de una causa de justificación). Así, la antinormatividad propia de un hecho constitutivo de homicidio es la propiedad secundaria de un comportamiento que soporta una descripción que expresa la satisfacción de las propiedades exigidas por la formulación del contenido de la prohibición, es decir, la propiedad de ser un comportamiento que consiste en la causación de la muerte de otro.

Por ende, el desconocimiento de las propiedades primarias del comportamiento que fundamentan su antinormatividad implica, a su vez, el desconocimiento de su antinormatividad. Quien dispara letalmente contra un ser humano vivo, creyendo erróneamente que se trata de un espantapájaros, necesariamente desconoce la específica antinormatividad de su comportamiento, que es relativa a su descripción (objetiva) como un comportamiento consistente en causar la muerte de otro ser humano ${ }^{42}$. Por eso,

${ }^{39}$ Esto, porque la representación de la concurrencia de circunstancias que objetivamente realizarían el supuesto de hecho de una causa de justificación conlleva, de acuerdo con la mejor teoría disponible, una exclusión de la imputación del hecho a título de infracción de deber dolosa. Véase infra, nota 46.

${ }^{40}$ Para este concepto de actitud proposicional, véase sólo Tugendhat, E., Introducción a la filosofía analítica, Gedisa, Barcelona, 2003, pp. 59 ss., 69 s. Una actitud proposicional es la actitud de un sujeto cuyo objeto es una proposición. La creencia (o bien, la expectativa o el temor) de un sujeto de que su muerte es inminente constituye una actitud proposicional de ese sujeto, cuyo contenido está constituido, a su vez, por la proposición identificada con la expresión "que su muerte es inminente".

41 Al respecto Mañalich, J. P., Nötigung und Verantwortung, Nomos, Baden-Baden, 2009, pp. 41 ss.; Mañalich, J. P., "Norma e imputación como categorías del hecho punible”, en Revista de Estudios de la Justicia 12, 2010, pp. $171 \mathrm{~s}$.

42 Esto muestra lo insostenible de la pretensión de reconocer una diferencia categorial, con relevancia para la imputación jurídico-penal, entre error e ignorancia. Así sin embargo van Weezel, A., Error y mero desconocimiento en derecho penal, LegalPublishing, Santiago, 2008, pp. 52 ss. Pues la función del error es, precisamente, hacer posible la constatación de una falta de conocimiento, esto es, una constatación de ignorancia. Esto no se sigue de una "omnipresencia del dolo como categoría psicológica de imputación" (Ibíd., p. 46), sino únicamente de la hipótesis coherentista (u "holista") que gobierna la adscripción de actitudes proposicionales. Véase ya Binding, K., La culpabilidad en derecho penal, BdF, Montevideo/Buenos Aires, 2009, p. 66. Una creencia errónea sirve de base para la inferencia de una falta de conocimiento, en la medida en que la proposición erróneamente tenida por verdadera sea incompatible con la proposición cuya verdad es correlativamente ignorada: puesto que un mismo objeto no puede ser, al mismo tiempo, un espantapájaros y un ser humano vivo, la creencia (errónea) de que el objeto del disparo constituiría un espantapájaros (= error) fundamenta el desconocimiento de que se trata de un ser humano vivo (= ignorancia). Por supuesto, no es conceptualmente imposible imaginar una situación en que un sujeto crea que un mismo objeto es tanto un espantapájaros como un ser humano vivo. Pero aquí el defecto de imputación no concernirá la falta de 
todo error de tipo implica un correspondiente error de prohibición ${ }^{43}$, sin que un error de prohibición, a la inversa, implique un correspondiente error de tipo. Ciertamente, esto no quiere decir que el autor del disparo no pueda representarse la antinormatividad de su comportamiento bajo una descripción alternativa -precisamente, la descripción que se corresponde con su creencia errónea. Quien erróneamente cree disparar sobre un espantapájaros (ajeno) puede representarse, también erróneamente, la antinormatividad del comportamiento así descrito, por ejemplo, bajo la prohibición de una causación de daño a una cosa ajena ${ }^{44}$. Todo error de tipo invertido, que fundamenta -como en el ejemplo- el dolo de una tentativa inidónea, implica a su vez un error de prohibición invertido, que fundamenta la consciencia de la antijuridicidad necesaria para la culpabilidad por el injusto (subjetivo) de esa tentativa inidónea. Pero al revés, no todo error de prohibición invertido implica un error de tipo invertido, lo cual es justamente el caso tratándose de un mero "delito putativo".

Lo anterior es de interés por dos razones. La primera consiste en que la consciencia (“actual”) de la antijuridicidad del hecho siempre faltará tratándose de un injusto (subjetivo) imprudente, incluso en casos de imprudencia consciente, en la medida en que la demarcación entre dolo (eventual) e imprudencia (consciente) se trace con arreglo a un criterio (estrictamente) cognoscitivo ${ }^{45}$. Pues en estos términos sólo hay dolo eventual si el destinatario de la norma reconoce, con un grado de probabilidad con relevancia para la decisión, la posibilidad concreta de que su hecho satisfaga la descripción que le confiere relevancia típica, esto es, que satisfaga las propiedades primarias de las cuales depende su antinormatividad.

La segunda razón es la determinante para lo que aquí interesa. Dado que sólo puede haber consciencia ("actual”) de la antijuridicidad en relación con un hecho doloso, esto hace posible identificar la precisa función de imputación del dolo, a saber: posibilitar la consciencia de la antijuridicidad como criterio de culpabilidad por el injusto. A esto se reduce, exclusivamente, la así llamada "función de alerta" (o de "llamada de atención") del dolo ${ }^{46}$. Si recién la adscripción de culpabilidad fundamenta el carácter reprochable

dolo, sino una falta de capacidad de culpabilidad por "locura o demencia". Véase Moore, M., Placing Blame, Clarendon Press, Oxford, 1997, p. 484, nota 8.

${ }^{43}$ Véase Jakobs, G., Strafrecht Allgemeiner Teil, 2a ed., Walter de Gruyter, Berlín, 1991, 19/34.

${ }^{44}$ Véase Hruschka, J., "El objeto del juicio de antijuricidad según el derecho penal actual”, en del mismo, Imputación y derecho penal, Thomson/Aranzadi, Navarra, 2005, pp. 101 ss., p. 107, nota 19, quien no advierte, sin embargo, la falta de concreción del objeto de la consciencia de la antijuridicidad en casos de "doble error": si el agente erróneamente asume que la persona sobre quien realiza el acceso carnal por vía vaginal es una mujer mayor de 14, aunque menor de 18 años (= error de tipo), pero al mismo tiempo asume, también erróneamente, que estaría per se prohibido semejante contacto sexual (aun no abusivo) con una mujer menor de 18 años (= error de prohibición invertido), el error de tipo excluye el dolo, y el error de prohibición invertido sólo fundamenta un "delito putativo". Ésta es la consecuencia de que tal "consciencia de la antijuridicidad" del hecho no esté fundamentada en la correspondiente consciencia (de las circunstancias) del hecho, esto es, en el dolo.

45 Ya Binding, K., Die Normen und ibre Übertretung II, 4ª ed., Scientia Verlag, Aalen, 1965 [orig.: 1922], pp. 314, 325 ss.

${ }^{46}$ En cambio, no es posible fundamentar tal función de alerta en relación con la representación de la falta de realización de las circunstancias de las cuales depende la satisfacción del supuesto de hecho de una 
del hecho, y si el objeto del reproche está constituido por un déficit de fidelidad al derecho manifestado en el no-seguimiento de una norma, entonces el reproche por un no-seguimiento consciente -esto es, doloso- de la norma exige la consciencia (actual) de la antijuridicidad del hecho. Una adscripción de dolo que no llega a fundamentar, en definitiva, una adscripción del correspondiente conocimiento de la antijuridicidad, no es más que la adscripción de un dolo estéril, esto es, de un dolo que carece de relevancia, al menos directa, para el reproche de culpabilidad.

\section{LA CONEXIÓN FUNCIONAL ENTRE DOLO Y CONOCIMIENTO DE LA ANTIJURIDICIDAD}

Lo anterior no quiere decir, en modo alguno, que no sea posible distinguir, analíticamente, entre el conocimiento constitutivo del dolo del hecho y el conocimiento constitutivo de la consciencia de la antijuridicidad del hecho. Esto, empero, ha sido puesto en cuestión por Jakobs, quien llegara a proclamar "la identidad del dolo y el conocimiento del injusto" ${ }^{47}$. No es casualidad que, a favor de esta tesis, Jakobs acuda al mismo argumento con que se intentara, hace ya mucho tiempo, invalidar la distinción entre error de hecho y error de derecho: su supuesta impracticabilidad en relación con los así llamados "elementos normativos del tipo delictivo".

Jakobs recurre, específicamente, al ejemplo de la exigencia de ajenidad de la cosa bajo la tipificación del hurto: "el dolo respecto de ello viene dado [...] por el conocimiento de (al menos la co-)propiedad [sic] de otro, en definitiva, el conocimiento de que existen normas que regulan las relaciones respecto de las cosas, y de que, según esas normas, una cosa determinada se encuentra (también) adscrita a otra persona", de modo tal, agrega Jakobs, que "[e]se conocimiento no es otra cosa que el conocimiento de la prohibición de destruir la cosa, de apropiarse de ella, etc., sin consentimiento del otro" ${ }^{48}$. Si esto es correcto, afirma Jakobs, entonces la tesis podría generalizarse hasta alcanzar cualquier otro ámbito delictivo, por ejemplo, el ámbito de los "delitos contra las personas en sentido amplio". Pues incluso el elemento "ser humano" -o el elemento "otro"- en el contexto de la tipificación del homicidio contaría como un elemento normativo, pues "[1]o que se destruye es la propiedad sobre el cuerpo".

causa de justificación, que es precisamente el argumento finalista a favor de la mal llamada "teoría estricta de la culpabilidad", que entiende que la suposición errónea de las circunstancias de las cuales depende la realización del supuesto de hecho de una causa de justificación constituiría un error de prohibición (indirecto), y no un error de tipo (permisivo). Véase el argumento en Welzel, H., Derecho Penal Alemán, $4^{a}$ ed., Ed. Jurídica de Chile, Santiago, 1997, p. 199. Concluyentemente en la dirección contraria, y demostrando lo errado de la terminología, Hruschka, J., “¿Realmente es 'limitada' la teoría 'limitada' de la culpabilidad? Adiós a un debate", en del mismo, Imputación y derecho penal, Thomson/Aranzadi, Navarra, 2005, pp. 127 ss., 142 s. Al respecto también Mañalich, J.P., "Consideraciones acerca del error sobre la concurrencia de los presupuestos objetivos de las causas de justificación”, Revista de Estudios de la Justicia 3, 2003, pp. 147 ss., 151 ss.

47 Véase Jakobs, G., "Dolus malus”, en InDret 4/2009, especialmente pp. 10 ss.

${ }^{48}$ Ibid., p. 11. 
Dejando de lado las implicaciones de esta muy problemática postulación de una relación de propiedad sobre el propio cuerpo $^{49}$, hay que notar que la premisa sobre la cual reposa la tesis global de Jakobs no está exenta de dificultades. Pues la distinción misma entre elementos descriptivos y elementos normativos, al menos si se la entiende como indicativa de un dualismo ontológico, es filosóficamente problemática, en tanto aparece comprometida con una epistemología distintivamente positivista ${ }^{50}$. Ello se muestra en la noción de que la satisfacción de un elemento descriptivo tendría que ser verificable mediante una operación de percepción sensorial, mientras que la satisfacción de un elemento normativo sería siempre dependiente de una operación de "captación intelectual" 51 . En contra de tal noción, cabe apuntar que la pregunta por la satisfacción de los elementos o componentes semánticos de una descripción o definición típica es equivalente a la pregunta de si, en atención a un determinado complejo de circunstancias, se satisfacen las condiciones de verdad de una determinada predicación: a saber, la predicación de una determinada propiedad, designada por el concepto que se corresponde con el elemento típico respectivo (“cosa ajena”, "ser humano vivo”, etc.), de tal o cual objeto referencial, ya sea el propio comportamiento, o bien el objeto sobre el cual éste incide, etc.

Desde este punto de vista, es irrelevante si la propiedad o característica en cuestión tiene estatus natural o institucional, pues en todo caso se tratará de una propiedad cuya realización constituye una cuestión de hecho, esto es, cuya realización puede ser objeto de constatación. Piénsese, por ejemplo, en la atribución de la propiedad designada por la descripción "menor de 14 años", que tiene que ser satisfecha por la víctima de un hecho constitutivo de violación en el sentido del art. 362 del Código Penal. A este respecto, no parece tener sentido la sugerencia de que la comprobación de la satisfacción de semejante elemento del tipo delictivo pudiera ser dependiente o bien de una percepción sensorial, o bien de una valoración ${ }^{52}$. Lo importante de esto es que al colapsar la distinción entre elementos descriptivos y elementos normativos, la distinción colapsa -como siemprepor ambos lados. Por ello, carece de sentido asumir, como lo propone Jakobs, que "en realidad" todo elemento descriptivo no es sino un elemento normativo. Pues si la noción de un elemento ("puramente") descriptivo pierde su sentido, también lo pierde la noción de un elemento ("puramente") normativo ${ }^{53}$.

49 Ibíd., p. 12. Para una crítica de la concepción (peyorativamente) "idealista" de la personalidad en Jakobs, véase Mañalich, J. P., Nötigung und Verantwortung, Nomos, Baden-Baden, 2009, pp. 266 ss.

${ }^{50}$ Por "positivismo", en este contexto, se entiende lo que, algo gruesamente, la filosofía de la ciencia conoce como "positivismo lógico" o "empirismo lógico"; no se trata, en modo alguno, de "positivismo jurídico".

51 Así Welzel, H., Derecho Penal Alemán, 4a ed., Ed. Jurídica de Chile, Santiago, 1997, pp. 90 ss.

${ }^{52}$ Fundamental al respecto, mostrando cómo el dualismo hecho-valor depende de una definición empirista del concepto de hecho (asumida por el positivismo lógico), Putnam, H., The Collapse of the Fact/ Value Dichotomy, Harvard University Press, Cambridge, Mass., 2002, pp. 7 ss., 28 ss., quien ofrece un muy pertinente ejemplo relativo a la propiedad designada por el adjetivo "cruel" (pp. 24 ss., 34 ss.).

53 Así ya Radbruch, G., "Sobre el sistema de la teoría del delito", Revista Electrónica de Ciencia Penal y Criminología 12-r1, 2010, pp. 8 s.: "a la postre, no existe elemento típico alguno que tampoco sea descriptivo y normativo a la vez". 
Pero incluso de aceptarse que esta última noción pudiera mantener su sentido, de ello no se sigue -y esto es lo que aquí interesa- que sea plausible el argumento de Jakobs acerca de la imposibilidad de diferenciar el conocimiento del hecho y el conocimiento de la antijuridicidad del hecho. Para volver a su ejemplo inicial: la razón por la cual podría pensarse que el dolo de un delito de apropiación resulta inseparable del conocimiento de la prohibición de la afectación de la propiedad ajena radica en que el concepto de propiedad $-y$, por ende, el de ajenidad- es uno normativamente cargado. Esto, porque el hecho de que un objeto cualquiera cuente como una cosa (corporal, mueble y) ajena es un hecho institucional, dado que la ajenidad de una cosa es dependiente de la existencia de reglas constitutivas que le confieren el estatus de objeto de propiedad de otro. Pero nada de esto significa que no pueda diferenciarse la pregunta de si un sujeto sabe (o cree) que se dan circunstancias de hecho que hacen aplicable, objetivamente, el predicado "cosa ajena", por una parte, de la pregunta de si ese mismo sujeto sabe (o cree) que el predicado "cosa ajena" es aplicable en las circunstancias objetivamente dadas, por otra ${ }^{54}$. Lo primero concierne la representación de la satisfacción de las condiciones de verdad de una proposición (“esta cosa es ajena”); lo segundo, en cambio, la representación del sentido o alcance de los conceptos a través de los cuales se articula esa proposición, incluido, por ejemplo, el predicado "cosa ajena" 55 .

Ahora bien, tal distinción entre un error de verdad y un error de sentido se corresponde exactamente con la distinción entre en un error excluyente del dolo y un error excluyente de la consciencia de la antijuridicidad, respectivamente ${ }^{56}$. Pero para advertir esto resulta imprescindible reconocer que una adscripción de dolo sólo es posible bajo la bipótesis de un (acabado) conocimiento de la norma cuyo contenido se corresponde con la proposición que el destinatario ha de hacer verdadera (tratándose de un mandato) o no ha de hacer verdadera (tratándose de una prohibición). Así, sólo bajo la hipótesis de que el sujeto conoce el sentido y alcance de la prohibición de apropiarse de una cosa ajena -lo cual también abarca el sentido (o alcance) del predicado "cosa ajena"- puede uno determinar si su conocimiento de las circunstancias (fácticas) podía servirle de base para formarse la intención, con arreglo a esa norma, de evitar la realización del tipo delictivo 57 .

${ }^{54}$ Así Neumann, U., "Regel und Sachverhalt in der strafrechtlichen Irrtumsdogmatik", en Paeffgen $e t$ al (coord.), Strafrechtswissenschaft als Analyse und Konstruktion. Festschrift für Ingeborg Puppe zum 70. Geburtstag, Duncker \& Humblot, Berlín, 2011, pp. 181 s.; las consecuencias que Neumann extrae (Ibíd., pp. 182 ss.), sin embargo, para la demarcación entre tentativa (inidónea) y delito putativo, tratándose de casos en que un sujeto yerra acerca del sentido de los conceptos que designan cualidades institucionales ("cosa ajena"), se explica por su desconocimiento de que, por definición, el error acerca del alcance de una regla no puede constituir un error acerca de las circunstancias que, objetivamente, resultan subsumibles bajo el alcance de una regla. Cuestión distinta es que uno y otro error puedan coincidir, tal como sucede en los casos de "doble error”. Véase supra, nota 44.

55 Fundamental Kindhäuser, U., "Acerca de la distinción entre error de hecho y error de derecho”, en VV.AA., El error en el derecho penal, Ad-Hoc, Buenos Aires, 1999, pp. 139 ss.

56 Ibid., pp. 149 ss.

${ }^{57}$ Ibid., pp. 151 ss. 
O para dar otro ejemplo: si un sujeto con motivaciones racistas dispara un arma de fuego, letalmente, sobre una persona perteneciente a un determinado grupo étnico, en la creencia de que no se trataría de "otro", en el sentido de la tipificación del homicidio, entonces para determinar si el hecho le es imputable -en el nivel del injusto (subjetivo) - a título de dolo hay que preguntarse si, bajo la suposición de que el autor hubiera conocido perfectamente el sentido y alcance de la prohibición del homicidio -que es precisamente lo que en el caso no se da-, su representación de las circunstancias fácticas objetivamente dadas le habría posibilitado formarse la intención de evitar el disparo, en pos del seguimiento de la prohibición. Y la respuesta, entonces, es ciertamente afirmativa. La creencia errónea del autor constituye un error conceptual (o de sentido) -en el cual se expresa, por lo demás, un muy serio error moral de su parte-, que sólo podría llegar a tener relevancia para la imputación en la medida en que efectivamente implicase una falta de conocimiento de la antijuridicidad del hecho, es decir, a modo de un error de prohibición.

Por ende, no se trata de que no resulte posible distinguir, conceptualmente, entre un error incompatible con la adscripción del dolo "natural" y un error incompatible con la adscripción del conocimiento de la antijuridicidad. Es notable, por lo demás, que la posibilidad de una nítida diferenciación entre el conocimiento de las circunstancias fácticas de las cuales depende (objetivamente) la antinormatividad del hecho, por un lado, y el conocimiento mismo de su antinormatividad, por otro, fuera advertida por algunos de los partidarios más acérrimos de la "vieja” teoría del dolo, que precisamente define el dolo como integrando ambos niveles de conocimiento ${ }^{58}$. Lo cual dista de ser una casualidad. Pues sólo diferenciando estructuralmente ambos niveles de conocimiento, con relevancia para la imputación, se vuelve reconocible la conexión funcional entre uno y otro.

Según ya se mostrara, en esta conexión funcional descansa la función indiciaria o de llamada de atención del dolo: sólo el conocimiento de las circunstancias de las cuales depende la realización del tipo delictivo pone al agente en posición de formarse la intención de evitar su realización, en pos del seguimiento de la norma. Esto tiene una consecuencia fundamental, que afecta la evaluación de la clásica disputa entre la teoría del dolo y la teoría de la culpabilidad. Es correcto mantener, en el sentido de la teoría de la culpabilidad, que el conocimiento de las circunstancias que objetivamente fundamentan la antinormatividad del hecho pertenece a un nivel de imputación que es anterior al nivel de imputación en el cual se hace relevante el conocimiento de la propia antinormatividad del hecho; esto se sigue, en efecto, de la distinción entre el juicio de infracción de deber y el juicio de culpabilidad por la infracción de deber. Pero

${ }^{58}$ Véase Mezger, E., Tratado de Derecho Penal II, Ed. Revista de Derecho Privado, Madrid, 1957, pp. 103 ss. En igual sentido ya Binding, K., La culpabilidad en derecho penal, BdF, Montevideo/Buenos Aires, 2009, pp. 84 s., quien diferenciaba el "error sobre un elemento de la acción en sentido estricto", por una parte, y el "error acerca del carácter prohibido de la concreta acción”, por otra. Lo distintivo de una teoría del dolo, así entendida, está en la afirmación de la equivalencia de los efectos de una y otra forma de error: exclusión de la culpabilidad dolosa. 
esto no significa, en modo alguno, que de ello se sigan, con una pretensión de vinculación analítica, las consecuencias institucionales que el legislador puede asociar a esa distinción conceptual.

Los ordenamientos que, como el alemán y el español, hacen posible la afirmación de una culpabilidad por un hecho doloso prescindiendo de la exigencia de conocimiento ("actual") de la antijuridicidad, admiten, en tal medida, un quiebre funcional en referencia a la función de fundamentación de la culpabilidad que desempeña el injusto subjetivo $^{59}$. Ciertamente, la medida de este quiebre funcional es relativa a cuál sea la específica consecuencia punitiva legalmente asociada al mismo: la medida del quiebre funcional es mayor en el derecho alemán, donde el error de prohibición vencible da lugar, a lo sumo, a una rebaja facultativa de pena ( $\$ 17$ StGB), que en el derecho español, donde el error de prohibición vencible se traduce en una rebaja, obligatoria para el tribunal, de uno o dos grados (art. 14.3 CPE). Por supuesto, no hay obstáculo institucional alguno que hable en contra de tal régimen, dado que el legislador es soberano para equiparar la expresión punitiva de formas de reproche que descansan en criterios de imputación divergentes.

Pero lo que no puede obviarse es la constatación de que bajo tales regímenes legales lo que se establece es, precisamente, una equiparación punitiva de formas de reproche heterogéneas. Pues el reproche por un no-seguimiento consciente (o "a sabiendas") de la norma sólo se deja fundamentar si el sujeto quebranta la norma conociendo ("actualmente”) la antinormatividad de su comportamiento. Si el agente no se representa la antijuridicidad del hecho, entonces el quebrantamiento de la norma sólo le es reprochable en virtud de un criterio de imputación extraordinaria, en el sentido de que el carácter vencible del error de prohibición fundamenta la responsabilidad del sujeto por ese mismo error, puesto que entonces el sujeto pudo evitar, de modo fiel a derecho, su propio déficit de capacidad de seguimiento de la norma. Y nada de esto se ve alterado por la definición eufemística del respectivo requisito de la culpabilidad como un mero "conocimiento potencial" de la antijuridicidad. Pues la expresión "conocimiento potencial" no es más que una metáfora que sugiere la inexistencia de conocimiento, asociada a la posibilidad (y exigibilidad) del mismo ${ }^{60}$. Cuando el requisito por defecto para la atribución de culpabilidad es identificado, dogmáticamente, con un mero "conocimiento potencial" de la antijuridicidad, lo que en efecto se está reconociendo es la aceptación institucional de un criterio de imputación extraordinaria como el criterio de imputación por defecto.

Para determinar con exactitud el ámbito en que tal criterio de imputación resulta operativo por defecto -al menos en ordenamientos que contemplan reglas como las de los códigos alemán y español-, es imprescindible detenerse en la estructura precisa de la conexión funcional entre dolo y consciencia de la antijuridicidad. Pues de acuerdo con lo ya sostenido, la consciencia de la antijuridicidad, relevante para la culpabilidad por

${ }^{59}$ Véase Kindhäuser, U., “Acerca de la distinción entre error de hecho y error de derecho”, en VV.AA., El error en el derecho penal, Ad-Hoc, Buenos Aires, 1999, p. 161.

${ }^{60}$ Véase Jakobs, G., Strafrecht Allgemeiner Teil, $2^{\mathrm{a}}$ ed., Walter de Gruyter, Berlín, 1991, 19/30. 
un injusto doloso, tiene que poder ser entendida como la representación de la específica antinormatividad del hecho que es posibilitada por la representación de las circunstancias fácticas en que consiste, a su vez, el dolo.

Pero ello no significa que la representación, por parte del autor, del carácter específicamente antinormativo del hecho, tenga que consistir en aquel conocimiento que es dado por supuesto, a modo de hipótesis, cuando se determina el dolo como criterio de la imputación a título de infracción de deber, esto es, el conocimiento cabal del sentido y alcance de la norma respectiva. Antes bien, para la consciencia ("actual") de la antijuridicidad es suficiente que el autor infiera el carácter específicamente antinormativo del hecho a partir de su conocimiento de las circunstancias fácticas de las cuales depende la realización del tipo ${ }^{61}$. En la muy acertada formulación de Binding, esto no exige en modo alguno que el autor llegue a subsumir, en sentido técnico, el hecho bajo el tipo delictivo correspondiente, sino sólo que llegue a la conclusión de que su comportamiento, en atención a las propiedades fácticas (naturales o institucionales) que objetivamente fundamentan su antinormatividad, ha de ser un comportamiento contrario a derecho, precisamente en atención a su descripción como un comportamiento que exhibe esas propiedades ${ }^{62}$. Es recién en este nivel, y no en el de la determinación del dolo (del hecho) por referencia al conocimiento de las circunstancias fácticas de las cuales depende, objetivamente, la realización del tipo, que cabe recurrir a la así llamada "valoración paralela en la esfera del lego", precisamente en la adscripción del conocimiento de la antijuridicidad ${ }^{63}$.

Y esta consciencia de la específica antinormatividad del hecho, por otra parte, no necesita conllevar una representación rayana en la certeza, sino que es suficiente lo que, siguiendo a Silva Sánchez, cabe denominar un "conocimiento eventual de la antijuridicidad" 64 . Lo importante es advertir que esto se sigue, sin más, del reconocimiento de la función indiciaria del dolo. Pues si el dolo, definido en su forma básica como dolo eventual, se satisface con una representación, con un grado de probabilidad relevante para la decisión, de la posibilidad concreta de la realización del tipo delictivo, entonces ese dolo sólo podrá fundamentar una representación equivalente, definida por el mismo grado de probabilidad, del carácter antinormativo del hecho. Para decirlo una vez más con Binding: el conocimiento de la antijuridicidad subsiste, en el caso normal, "a pesar de la duda" 65 .

Lo anterior sugiere que la plausibilidad del reconocimiento de un error de prohibición que excluya la consciencia de la antijuridicidad a pesar del carácter doloso del hecho es

${ }^{61}$ Kindhäuser, U., “Acerca de la distinción entre error de hecho y error de derecho”, en VV.AA., El error en el derecho penal, Ad-Hoc, Buenos Aires, 1999, pp. $161 \mathrm{~s}$.

${ }^{62}$ Binding, K., La culpabilidad en derecho penal, BdF, Montevideo/Buenos Aires, 2009, pp. 53 s.

${ }^{63}$ Así Kindhäuser, U., "Acerca de la distinción entre error de hecho y error de derecho”, en VV.AA., El error en el derecho penal, Ad-Hoc, Buenos Aires, 1999, p. 162.

${ }^{64}$ Silva Sánchez, J., "Observaciones sobre el conocimiento 'eventual' de la antijuridicidad", en, del mismo, Consideraciones sobre la teoría del delito, Ad-Hoc, Buenos Aires, 1998, pp. 259 ss.

${ }^{65}$ Binding, K., La culpabilidad en derecho penal, BdF, Montevideo/Buenos Aires, 2009, pp. 55 s. 
menor que lo que cabría imaginar a primera vista. Y ciertamente, mientras mayor sea la legitimidad material de la norma quebrantada, en el sentido de que ella constituya una norma autoevidente para el ciudadano, menor será el margen de plausibilidad de la invocación exitosa de un error de prohibición ${ }^{66}$. Esto explica, entre otras cosas, que el alegato de un error de prohibición siempre muestre mayor verosimilitud, prima facie al menos, tratándose de un extranjero.

\section{Dolus malus}

Según ya se mostrara, los ordenamientos que prevén una atenuación (facultativa u obligatoria) de pena en relación con el respectivo hecho doloso cuando existe un error de prohibición vencible en el autor, asumen un quiebre funcional en la fundamentación del reproche de culpabilidad. Pues en tal caso, el carácter doloso del injusto no se expresa en el carácter autoconsciente de la culpabilidad como culpabilidad por ese injusto. Ésta es, precisamente, la consecuencia de todo (genuino) error de prohibición, sea vencible o invencible. Lo característico del error de prohibición vencible se encuentra, más bien, en que el mismo deja subsistente la posibilidad de dirigir un reproche de culpabilidad por el hecho a su autor. Pero ese reproche, mediado por la afirmación del carácter vencible del error, descansa en un juicio de imputación extraordinaria.

Lo distintivo de la tradicional teoría del dolo consiste en su propuesta de solución, divergente a la mantenida por la teoría de la culpabilidad, para la determinación de la punibilidad y la penalidad del hecho así imputable. Bajo la solución propuesta por la teoría del dolo, el hecho ha de quedar sometido al régimen sancionatorio aplicable al correspondiente delito imprudente, precisamente porque la culpabilidad afirmada en atención al carácter vencible del error de prohibición se funda en la infracción de una exigencia de cuidado: la exigencia de cuidado cuya observancia habría puesto al autor en posición de advertir el carácter antinormativo del hecho. Se trata, en tal medida, de una "imprudencia en la evaluación jurídica" del hecho - por oposición a la imprudencia (stricto sensu) en la evaluación circunstancial del hecho ${ }^{67}$.

Lo que resta por clarificar es cuál sea el régimen, previsto por el Código Penal chileno, para los casos en que el error de prohibición vencible no se funda en un error de tipo vencible, esto es, en una falta de dolo ("natural") compensada por la imprudencia del autor como criterio de imputación de la infracción de deber a nivel de injusto; es

${ }^{66}$ A esto se reduce la relevancia heurística de la tradicional contraposición entre hechos constitutivos de mala in se y hechos constitutivos de mala probibita: la ilicitud de los primeros tendría que poder ser reconocida con total independencia del eventual conocimiento de la respectiva regulación.

${ }^{67} \mathrm{La}$ exigencia de cuidado relevante para la fundamentación de la imprudencia (stricto sensu) está referida a las medidas de precaución cuya adopción habrían puesto al autor en posición de asegurar su capacidad de acción necesaria para la evitación intencional de la realización del tipo. La exigencia de cuidado relevante para la fundamentación del carácter vencible del error de prohibición, en cambio, es relativa a las medidas de precaución cuya adopción habría puesto al autor en posición de inferir el carácter antinormativo de su actuar (u omitir) a partir de su conocimiento de las circunstancias del hecho. 
decir, para los casos de error de prohibición vencible en los cuales la falta de consciencia de la antijuridicidad descansa en la falta de inferencia, por parte del autor, del carácter antinormativo del hecho a partir de su efectivo conocimiento de las circunstancias fácticas dadas, que cuenta como el dolo del hecho.

La respuesta parece ser tan clara como categórica: el art. $2^{\circ}$ del Código Penal equipara las nociones de "dolo" y "malicia”, con lo cual cabría afirmar que el concepto de dolo hecho suyo por el legislador chileno se corresponde con el concepto de dolo asumido por la tradicional "teoría del dolo": el dolo integraría la consciencia ("actual”) de la antijuridicidad del hecho ${ }^{68}$. Pues eso es justamente lo que sugiere la equiparación de los términos "dolo" y "malicia": una definición de dolo como dolus malus ${ }^{69}$. La consecuencia de ello es conocida. El error de prohibición vencible excluiría el dolo, con lo cual el hecho sólo resultaría imputable a título de imprudencia, cuya punibilidad dependería, entonces, de que la ley prevea, específicamente, la punibilidad del respectivo delito imprudente, lo cual por regla general sólo es el caso tratándose de hechos constitutivos de delitos contra las personas, esto es, tipificados por disposiciones contenidas el Título VIII del Libro II del Código Penal, sin perjuicio de la posibilidad de una declaración específica de la punibilidad del respectivo delito imprudente en algún otro contexto regulativo.

Ésta es, en efecto, la lectura de la regulación legal que resulta de la adopción de la tradicional teoría del dolo. Lo que aquí se ha intentado, sin embargo, es sugerir la posibilidad de una lectura parcialmente discrepante, esto es: una lectura que asuma -en el sentido de la teoría de la culpabilidad- la diferenciación entre dolo y conocimiento de la antijuridicidad desde el punto de vista de su posición relativa en el respectivo nivel de imputación, pero que al mismo tiempo asuma -en el sentido de la teoría del dolo- la necesidad de conocimiento de la antijuridicidad como criterio de culpabilidad por el injusto doloso. Y lo que hay que fundamentar ahora es la plausibilidad de semejante lectura diferenciada, que pretende hacer operativa -con un cierto dejo de ironía- la unidad entre dolo y conocimiento de la antijuridicidad, proclamada por la teoría del dolo, a través de la diferenciación estructural proclamada de la teoría de la culpabilidad, frente a la regulación legal.

Esto, porque si bien el art. $2^{\circ}$ del Código Penal parece equiparar, sin más, las nociones de dolo y malicia, esta equiparación parece relativizarse en otros sectores de la regulación legal, fundamentalmente en aquellas disposiciones que expresamente incorporan una exigencia específica de "malicia" -aunque jamás de "dolo". Si "dolo" y "malicia” no fueran más que términos estrictamente sinónimos para el legislador, entonces semejante exigencia expresa de "malicia” no sería sino una redundancia. Pues, dado que la exigencia general de dolo opera por defecto, en virtud de la clausura de la

${ }^{68}$ Véase Novoa Monreal, E., Curso de Derecho Penal Chileno I, 3 a ed., Editorial Jurídica de Chile, Santiago, 2005 , pp. 477 ss., 537 ss., quien validaba, sin embargo, la tesis de una presunción de derecho del conocimiento de la significación jurídica del hecho de conformidad con la regla del art. $8^{\circ}$ del Código Civil.

${ }^{69}$ Así Etcheberry, A., Derecho Penal Parte General I, $3^{a}$ ed., Editorial Jurídica de Chile, Santiago, 1998, pp. 307 s. 
punibilidad de la imprudencia (art. $10 \mathrm{~N}^{\circ} 13 \mathrm{CP}$ ), la exigencia específica de "malicia" resultaría enteramente superflua ${ }^{70}$.

Para evitar esta constatación de una eventual redundancia legislativa, contraria a la máxima de la interpretación útil, podrían invocarse dos argumentos. El primero consistiría en sostener que la exigencia específica de "malicia" puede ser entendida como la exigencia de una forma más intensa de dolo, esto es, de dolo directo por oposición al dolo eventual ${ }^{71}$. El problema, sin embargo, es que esta estrategia contradice, más bien, la tesis de la estricta equiparación legal de "dolo" y "malicia": si "dolo" es igual a "malicia", y el dolo eventual cuenta como una forma de "dolo", entonces no es posible imaginar cómo el legislador podría excluir la relevancia de una forma de "dolo" exigiendo nada más que "dolo".

El segundo argumento consistiría en sostener que la interpretación en cuestión sí evita la redundancia, en la medida en que al exigir "malicia” el legislador estaría excluyendo la punibilidad del hecho respectivo, en tanto éste sólo resultase imputable a título de imprudencia. El problema, sin embargo, es que semejante argumento sólo funciona tratándose de aquellas exigencias específicas de "malicia" contenidas en disposiciones que tipifican hechos delictivos cuya punibilidad a título de imprudencia se encuentra legalmente prevista, es decir, en disposiciones pertenecientes al Título VIII del Libro II del Código Penal, lo cual únicamente ocurre tratándose de los arts. 395 y 396, que respectivamente tipifican los delitos de castración y de mutilación. Fuera de este ámbito, la interpretación en cuestión no logra eludir la atribución de un pleonasmo al legislador, contraviniendo así el principio de la interpretación útil.

Frente a esto, sin embargo, cabe explorar una interpretación alternativa, que procure relativizar la tesis de una estricta equivalencia entre las nociones legales de "dolo" y "malicia". Para ello, es de máxima relevancia considerar el problema en referencia al art. 342 del Código Penal, que tipifica las variantes típicas de aborto cuya realización es imputable, a personas distintas de la mujer embarazada, a título de dolo. El encabezado del art. 342 exige, en efecto, que el hecho sea cometido "maliciosamente". Puesto que el aborto, en virtud de su sola posición en el sistema de la regulación legal, no se encuentra configurado como una forma de delito contra las personas, no es admisible una interpretación de "maliciosamente" como equivalente a "dolosamente", pues ello implicaría la adscripción de una redundancia al legislador. Y en contra de esto no cabría aducir que, dado que el art. 343 tipificaría una forma de aborto cuya realización imputable no requeriría dolo, la exigencia de "malicia" en el art. 342 no sería redundante, puesto que, en tal medida, la regulación sí reconocería la punibilidad de una forma de aborto imprudente. Pues el art. 343 habla de "propósito" para referirse al dolo que no necesita darse, con tal que el estado de embarazo de la mujer sea notorio o bien conste al autor.

${ }^{70}$ Acerca de esta posibilidad interpretativa véase ya Amunátegui, F., "Maliciosamente" y "A Sabiendas" en el Código Penal Chileno, Ed. Jurídica de Chile, Santiago, 1961, pp. 46 s.

${ }^{71}$ Véase en relación con el aborto (art. 342), la castración (art. 365) y la mutilación (art. 366), Politoff, S., Grisolía, F. y Bustos, J., Derecho Penal Chileno. Parte Especial, $2^{a}$ ed., Editorial Jurídica de Chile, Santiago, 1993, pp. 148 s., 199, 201. 
Lo cual muestra, entonces, que la regulación no recurre a la noción de "malicia" para demarcar el ámbito de punibilidad del aborto doloso y del aborto imprudente.

Esto deja abierta la posibilidad de interpretar el término "maliciosamente", en el contexto del art. 342, como una exigencia específica de conocimiento de la antijuridicidad. Y lo interesante está en que hay buenas razones por las cuales el legislador pudo haber juzgado necesario o conveniente establecer tal exigencia específica ${ }^{72}$. Esto concierne directamente el estatus de la prohibición del aborto como una norma que está lejos de ser autoevidente para el ciudadano. Sobre todo en atención a la altísima conflictividad que esa prohibición muestra en relación con el reconocimiento de la igual autonomía de la mujer embarazada, es altamente probable que, a pesar del dolo ("natural"), el autor del hecho pueda no llegar a inferir su específica antinormatividad, ante todo en virtud de una eventual suposición errónea de la existencia de causas de justificación, es decir, en virtud de un posible error de prohibición indirecto (o "error de permisión") 73 . En este contexto, la exigencia expresa de "malicia" tendría que entenderse como una declaración legal de una exigencia de conocimiento de la antijuridicidad como requisito de la punibilidad del hecho, cuya satisfacción ha de ser exitosamente demostrada por el órgano persecutor.

\section{ERROR DE PROHIBICIÓN VENCIBLE E IMPRUDENCIA}

La pregunta cuya respuesta aún está pendiente es, sin embargo, la siguiente: ¿cuál es el régimen que el Código Penal chileno hace aplicable para los casos de error de prohibición vencible? El punto de partida para ello se halla en la consideración de que la equiparación de las nociones de "dolo" y "malicia”, en el contexto del art. $2^{\circ}$, no tiene que ser entendida como una declaración de equivalencia semántica, sino más bien como una indicación de la conexión funcional que cabe reconocer entre el dolo y el conocimiento de la antijuridicidad, esto es, entre dolo y malicia ${ }^{74}$, justamente en el sentido de que la culpabilidad en que se refleja el carácter doloso del hecho sólo puede

${ }^{72}$ Bajo la tesis aquí defendida, no es casualidad que tal exigencia figure también, por ejemplo, en el art. 374 bis inc. $2^{\circ}$, que tipifica un delito de mero almacenamiento o adquisición de material pornográfico en cuya producción hubiesen sido utilizados menores de edad, como en los arts. $1^{\circ}, 2^{\circ}$ y $4^{\circ}$ de la Ley $\mathrm{N}^{\circ} 19.223$, que tipifican delitos de sabotaje informático, destrucción y alteración de datos y divulgación de datos, respectivamente. Pues en todos estos casos se trata del reforzamiento jurídico-penal de prohibiciones que están lejos de ser autoevidentes para el ciudadano. De máxima relevancia resulta ser la circunstancia del establecimiento relativamente reciente de las mencionadas normas de sanción, pues ello sugiere que el uso correspondiente de "malicia" está lejos de ser un mero resabio anacrónico, expresivo de una deficiente técnica legislativa.

73 Indiciariamente en este sentido, Etcheberry, A., Derecho Penal Parte General I, $3^{\text {a }}$ ed., Editorial Jurídica de Chile, Santiago, 1998, p. 308.

${ }^{74}$ Esto es apenas sugerido por Garrido, M., Derecho Penal Parte General II, 4a ed., Editorial Jurídica de Chile, Santiago, 2005, pp. 106 s., aunque apoyándose en el escasamente concluyente argumento de que la conjunción "o" que conecta los términos "dolo" y "malicia” sería "alternativa y no equiparativa”. El problema es que esto es lo que debería ser demostrado, y no dado por sentado, por el argumento. 
consistir en una culpabilidad definida por el conocimiento de la antijuridicidad. Y esta forma de culpabilidad, la única funcionalmente congruente con el injusto subjetivo de un hecho doloso, puede ser entendida, a su vez, como la específica "voluntariedad", en los términos de la definición del inc. $1^{\circ}$ del art. $1^{\circ}$, del hecho constitutivo de un delito doloso $^{75}$.

Pero de acuerdo con la regla del inciso $2^{\circ}$ del art. $1^{\circ}$, el hecho ha de reputarse voluntario, salvo que conste lo contrario; es decir, el hecho doloso, en el sentido del art. $2^{\circ}$, ha de reputarse malicioso, salvo que se demuestre lo contrario. Luego, el régimen general de la regulación del Código Penal en relación con los presupuestos de la culpabilidad propia del delito doloso -que sólo se ve alterado allí donde la ley exige, expresamente, "malicia"- convierte el conocimiento de la antijuridicidad en objeto de una presunción simplemente legal ${ }^{76}$, la cual sólo resultará derrotada en la medida en que la defensa demuestre, exitosamente, la existencia de un error de prohibición ${ }^{77}$. Y si éste resulta ser un error vencible, entonces, excluyéndose el carácter malicioso del hecho, la punibilidad del mismo queda sometida al régimen de la imprudencia: a menos que su punibilidad como delito imprudente esté específicamente prevista por alguna disposición legal, el hecho sólo resultará punible, en tanto el mismo se encuentre tipificado bajo el Título VIII del Libro II del Código Penal, con arreglo a los arts. 490 y siguientes, que justamente exigen la inexistencia de "malicia" y no meramente la inexistencia de "dolo".

Lo anterior no se ve modificado si se toma en cuenta que el legislador ha establecido un régimen diverso en el art. 110 del Código Tributario, consistente en el reconocimiento de una eximente o atenuante en caso de que, tratándose de una persona "de escasos recursos pecuniarios, por su insuficiente ilustración o por alguna otra causa justificada", ella hubiese tenido "un conocimiento imperfecto del alcance de las normas infringidas". Pues el conocimiento de la antijuridicidad, según lo ya sostenido, no depende en modo alguno del conocimiento del alcance de la norma respectiva -pues de lo contrario cualquier error de subsunción podría implicar la inexistencia de consciencia de la antijuridicidad-, sino que se reduce a la inferencia de la antinormatividad del hecho a partir de la representación de las circunstancias fácticas de las cuales depende la realización del correspondiente tipo delictivo. Por ende, al establecer un régimen distinto, el art. 110 del Código Tributario pone de manifiesto que la exigencia general de malicia como forma de culpabilidad correlativa al eventual carácter doloso del hecho no se encuentra reconocida en el ámbito del derecho (penal) tributario. La disposición

${ }^{75}$ Con ello, la exigencia de voluntariedad del art. $1^{\circ}$ conserva su carácter común frente a la distinción legal entre el delito doloso y el delito imprudente, formulada en el art. $2^{\circ}$. Fundamental para esta interpretación, Bustos, J. y Soto, E.: “Voluntaria significa culpabilidad en sentido restringido", en Revista de Ciencias Penales XXIII, 1964, pp. 243 ss., 260 s.

76 Ibid., p. 261.

77 A diferencia de la tesis defendida por Amunátegui, F., "Maliciosamente" y "A Sabiendas" en el Código Penal Chileno, Ed. Jurídica de Chile, Santiago, 1961, pp. 56 ss., la tesis aquí defendida no parte de la base de la interpretación de la presunción de voluntariedad como una presunción de dolo; antes bien, esa presunción es sólo una presunción de la consciencia de la antijuridicidad, que se ve revertida, entonces, cada vez que el legislador formula una exigencia específica de (la comprobación de) "malicia". 
restringe, por ende, el alcance eximente del error de prohibición previsto (implícitamente) por el Código Penal, de modo que aquellos contribuyentes que no se encuentran en la situación descrita por la regla no pueden invocar un desconocimiento de la ilicitud de su actuar u omitir a modo de exoneración ${ }^{78}$.

La solución general que, por defecto, prevé el Código Penal para los casos de error de prohibición vencible consiste, entonces, en la exclusión del régimen de penalidad asociado a la exigencia de culpabilidad por un injusto doloso -esto es, de aquella que presupone una atribución de culpabilidad en la cual se refleja el carácter doloso del injusto (subjetivo)-, subsistiendo únicamente la aplicabilidad del régimen de penalidad correspondiente a la culpabilidad referida a un injusto imprudente, siempre que la ley prevea la punibilidad del hecho imputable a título de imprudencia en el ámbito delictivo correspondiente. La defensa de esta solución podrá parecer revisionista, pero ella no es más que la expresión de la referencia (funcional) de la culpabilidad al injusto. Pues en una culpabilidad no definida por el conocimiento de la antijuridicidad no se manifiesta el carácter doloso del injusto, en circunstancias de que la manifestación del injusto doloso en la culpabilidad es lo único que puede fundamentar su mayor reprochabilidad $^{79}$. Y esto tendría que contar como desiderátum para cualquier concepción que pretenda poder seguir entendiendo el delito como lo que es: "autorrealización de la culpabilidad" $"$.

\section{BIBLIOGRAFÍA}

Amunátegui, F., "Maliciosamente" y "A Sabiendas" en el Código Penal Chileno, Ed. Jurídica de Chile, Santiago, 1961.

BINDING, K., Lebrbuch des Gemeinen Deutschen Strafrechts I, 2a ed., Wilhelm Engelmann, Leipzig, 1902.

BINDING, K., Die Normen und ibre Übertretung, 4a ed., Scientia Verlag, Aalen, 1965 [orig.: 1922].

BInding, K., La culpabilidad en derecho penal, BdF, Montevideo/Buenos Aires, 2009.

Bustos, J. у Sото, E., "Voluntaria significa culpabilidad en sentido restringido", en Revista de Ciencias Penales XXIII, 1964, pp. 243-264.

${ }^{78}$ Ello no contraviene exigencia de legitimación alguna que pudiera ser vinculante para el legislador, dado que el art. $2^{\circ}$ del Código Penal, al igual que el art. 110 del Código Tributario, constituye una norma de rango legal: lex specialis (posterior) derogat lege generali (priori).

${ }^{79} \mathrm{La}$ explicación de la mayor severidad de la penalidad del delito doloso frente al delito imprudente no puede encontrarse, como propone van Weezel (véase van Weezel, A., Error y mero desconocimiento en derecho penal, Legal Publishing, Santiago, 2008, p. 40, nota 93), en que "la sociedad puede permitirse hacerlo", desde ya porque es estrictamente cierto que la sola posibilidad de que $\mathrm{X}$ sea el caso jamás puede explicar que $\mathrm{X}$ efectivamente sea el caso. Que la sociedad "pueda permitirse" reaccionar menos enérgicamente -y bajo una regla de numerus clausus, selectivamente- frente al quebrantamiento imprudente que frente al quebrantamiento doloso de una misma norma de comportamiento sugiere, más bien, que hay una razón para ello.

${ }^{80}$ Binding, K., Die Normen und ibre Übertretung II, 4a ed., Scientia Verlag, Aalen, 1965 [orig.: 1922], p. 293. 
Etcheberry, A., Derecho Penal Parte General I, $3^{\mathrm{a}}$ ed., Editorial Jurídica de Chile, Santiago, 1998.

Garrido, M., Derecho Penal Parte General II, $4^{a}$ ed., Editorial Jurídica de Chile, Santiago, 2005.

Hegel, G.F.W., Grundlinien der Philosophie des Rechts, Werke 7, Suhrkamp, Frankfurt a.M., 1986.

HruschKa, J., "La imputación ordinaria y extraordinaria en Pufendorf", en del mismo, Imputación $y$ derecho penal, Thomson/Aranzadi, Navarra, 2005, pp. 55 ss.

HruschKa, J., "Reglas de comportamiento y reglas de imputación”, en del mismo, Imputación $y$ derecho penal, Thomson/Aranzadi, Navarra, 2005, pp. 27 ss.

HruschKa, J., "El objeto del juicio de antijuridicidad según el derecho penal actual”, en del mismo, Imputación y derecho penal, Thomson/Aranzadi, Navarra, 2005, pp. 101 ss.

Hruschka, J., “¿Realmente es 'limitada’ la teoría ‘limitada' de la culpabilidad? Adiós a un debate”, en del mismo, Imputación y derecho penal, Thomson/Aranzadi, Navarra, 2005, pp. 127 ss.

Jakовs, G., Strafrecht Allgemeiner Teil, 2a ed., Walter de Gruyter, Berlín, 1991.

Jakobs, G., "El concepto jurídico-penal de acción", en del mismo, Estudios de Derecho Penal, Civitas, Madrid, 1997.

Jakoвs, G., "Dolus malus", en InDret 4/2009.

KINDHÄUSER, U., Gefährdung als Straftat, Vittorio Klostermann, Frankfurt a.M., 1989.

KINDHÄUSER, U., "Acerca de la distinción entre error de hecho y error de derecho”, en VV.AA., El error en el derecho penal, Ad-Hoc, Buenos Aires, 1999, pp. 139 ss.

Lesch, H., Der Verbrechensbegriff, Carl Heymanns Verlag, Colonia, 1999.

MAÑALICH, J.P., "Consideraciones acerca del error sobre la concurrencia de los presupuestos objetivos de las causas de justificación”, Revista de Estudios de la Justicia 3, 2003, pp. 147 ss.

MaÑalich, J.P., Nötigung und Verantwortung, Nomos, Baden-Baden, 2009.

Mañalich, J.P., “¿Reglas del entendimiento? Acerca de la ‘juridificación’ de la comunicación en la pragmática universal de Jürgen Habermas”, en Estudios Públicos 119, 2010, pp. 121 ss.

Mañalich, J.P., "Norma e imputación como categorías del hecho punible”, en Revista de Estudios de la Justicia 12, 2010, pp. 165 ss.

MaÑalich, J.P., Terror, pena y amnistía, Flandes-Indiano, Santiago, 2010.

Mezger, E., Tratado de Derecho Penal II, Ed. Revista de Derecho Privado, Madrid, 1957.

Moore, M., Placing Blame, Clarendon Press, Oxford, 1997.

Neumann, U., "Regel und Sachverhalt in der strafrechtlichen Irrtumsdogmatik", en Paeffgen et al. (coord.), Strafrechtswissenschaft als Analyse und Konstruktion. Festschrift für Ingeborg Puppe zum 70. Geburtstag, Duncker \& Humblot, Berlín, 2011, pp. 171 ss.

Novoa Monreal, E., Curso de Derecho Penal Chileno I, $3^{\text {a }}$ ed., Editorial Jurídica de Chile, Santiago, 2005.

PAwlik, M., “`¿El paso más importante de la dogmática de la última generación?’. Reflexiones para la diferenciación entre injusto y culpabilidad en derecho penal”, en del mismo, $L a$ libertad institucionalizada. Estudios de filosofía jurídica y derecho penal, Marcial Pons, Madrid/ Barcelona/Buenos Aires, 2010, pp. 109 ss.

Politoff, S., Grisolía, F. y Bustos, J., Derecho Penal Chileno. Parte Especial, $2^{\mathrm{a}}$ ed., Editorial Jurídica de Chile, Santiago, 1993.

Putnam, H., The Collapse of the Fact/Value Dichotomy, Harvard University Press, Cambridge, Mass., 2002.

Radbruch, G., “Sobre el sistema de la teoría del delito”, Revista Electrónica de Ciencia Penal y Criminología 12-r1, 2010.

Silva SÁNCHEZ, J., "Observaciones sobre el conocimiento 'eventual' de la antijuridicidad”, en del mismo, Consideraciones sobre la teoría del delito, Ad-Hoc, Buenos Aires, 1998, pp. 259 ss. 
Silva Sánchez, J., "Introducción: Dimensiones de la sistematicidad de la teoría del delito", en Wolter y Freund (ed.), El sistema integral del Derecho penal, Marcial Pons, Madrid/Barcelona, 2004, pp. 15 ss.

Tugendhat, E., Introducción a la filosofía analítica, Gedisa, Barcelona, 2003.

Van Weezel, A., Error y mero desconocimiento en derecho penal, Legal Publishing, Santiago, 2008.

VAN WeEzel, A., "Intervención delictiva y garantismo penal”, Zeitschrift für Internationale Strafrechtsdogmatik 8, 2009, pp. 432 ss.

Welzel, H., Derecho Penal Alemán, $4^{a}$ ed., Ed. Jurídica de Chile, Santiago, 1997. 